\title{
Long-term visual and anatomic outcomes after photodynamic therapy for symptomatic circumscribed choroidal hemangioma
}

\author{
Resultados visuales y anatómicos a largo plazo después de la terapia fotodinámica para \\ el hemangioma coroideo circunscrito sintomático
}

\begin{abstract}
Jesus H. Gonzalez-Cortes ${ }^{1 *}$, Abraham Olvera-Barrios ${ }^{1}$, Jose R. Perez-Salas ${ }^{1}$, Hugo A. Trevino-Rodríguez, Ezequiel E. Trevino-Cavazos', Jesus E. Gonzalez-Cantu² and Jesus Mohamed-Hamsho'

'Departamento de Oftalmología; 'Grupo de Investigación Bpinvest. Facultad de Medicina y Hospital Universitario "Dr. José Eleuterio González", Universidad Autónoma de Nuevo León, Monterrey, México
\end{abstract}

\begin{abstract}
Circumscribed choroidal hemangiomas (CCHs) are relatively rare. We report the response of a symptomatic $\mathrm{CCH}$ to photodynamic therapy (PDT). A 70-year-old male presented with blurred vision of the left eye (OS). Best-corrected visual acuity (BCVA) was 20/60 right eye and 20/160 OS. Biomicroscopy revealed bilateral cataracts. Diagnosis of CCH was made fundoscopically for OS and confirmed with optical coherence tomography (OCT). One session of PDT with individualized parameters was administered. After 2 months, anatomical improvement was evidenced with OCT and BCVA was 20/60. After cataract surgery, his BCVA was of 20/25 and remained stable. PDT showed excellent anatomic and visual results after a 2-year follow-up.
\end{abstract}

KEY WORDS: Circumscribed choroidal hemangioma. Photodynamic therapy. Optical coherence tomography. Optical coherence tomography-angiography.

\section{Resumen}

Los hemangiomas coroideos circunscritos son relativamente raros. Reportamos la respuesta de uno sintomático con terapia fotodinámica. Un hombre de 70 años presentó visión borrosa en el ojo izquierdo. La mejor agudeza visual corregida fue de 20/60 en el ojo derecho y de 20/160 en el izquierdo. La biomicroscopía demostró catarata en ambos ojos. En el ojo izquierdo se diagnosticó un hemangioma coroideo circunscrito confirmado con tomografía de coherencia óptica. Se administró una sesión de terapia fotodinámica con parámetros individualizados. Dos meses después se observó mejoría anatómica en la tomografía de coherencia óptica, y la mejor agudeza visual corregida fue de 20/60. Después de la cirugía de catarata, la mejor agudeza visual corregida fue de 20/25 y tuvo estabilidad. La terapia fotodinámica mostró excelentes resultados anatómicos y funcionales a los 2 años.

PALABRAS CLAVE: Hemangioma coroideo circunscrito. Terapia fotodinámica. Tomografía de coherencia óptica. Angiografía.

\author{
Correspondence: \\ *Jesús Hernán González-Cortés \\ Departamento de Oftalmología \\ Hospital Universitario y Facultad de Medicina \\ Monterrey, Nuevo León, México \\ E-mail: drjesusgzz@gmail.com
}

Cir Cir. 2019;87:224-229

Contents available at PubMed www.cirugiaycirujanos.com 


\section{Background}

Choroidal hemangioma is a benign, relatively rare vascular hamartoma that can present as a solitary, isolated lesion: circumscribed choroidal hemangioma $(\mathrm{CCH})$, and less frequently, as an extensive lesion associated with Sturge-Weber syndrome: diffuse choroidal hemangioma ${ }^{1,2}$. Typically, $\mathrm{CCH}$ is seen as a discrete, smooth, round or oval, orange-red mass in the posterior pole with relation to the macular or peripapillary area ${ }^{3}$. On fluorescein angiography (FA), an early, diffuse hyperfluorescence is characteristic, whereas high to medium internal reflectivity on ultrasonography (US) is typical ${ }^{2}$. According to location and anatomic characteristics, a patient can be asymptomatic or present severe visual impairment ${ }^{3}$. Chronic subretinal fluid exudation from the tumor may result in serous retinal detachment (SRD), the principal cause of visual loss in these patients ${ }^{4}$.

Therapeutic measures are indicated when visual acuity (VA) decreases ${ }^{5}$. According to the current evidence, the use of photodynamic therapy (PDT) as the first-line treatment in patients with SRD can achieve tumor regression with visual improvement and/or stabilization ${ }^{1,4,6-8}$. We report the case of a successfully treated case of $\mathrm{CCH}$ with PDT as monotherapy and the anatomical changes during follow-up imaged with optical coherence tomography (OCT).

\section{Clinical Case}

A 70-year-old male with no relevant medical history presented to our outpatient ophthalmology clinic with a 3-week history of blurred vision, visual distortion, and referring a positive scotoma in the central visual field of the left eye. His best-corrected VA (BCVA) was of 20/60 for the right eye (OD) and 20/160 for the left eye (OS). Automated refraction revealed sphere (SPH) -3.75 and cylinder (CYL) -1.25 for OD, and SPH +3.50 and $C Y L-1.00$ for OS.

Anterior segment biomicroscopy revealed nuclear cataract in both eyes (OU) (nuclear opalescence grade 2 and nuclear color grade 2, according to the lens opacity classification score III) that did not correlate with the patient's VA of OS. The rest of the anterior segment examination was unremarkable OU. Intraocular pressure was $10 \mathrm{mmHg}$ OU. On posterior segment, examination under mydriasis of OS an isolated, oval, yellow-orange, and mottled elevated lesion of approximately 3 disc diameters with an associated SRD was identified in the temporoinferior macular area (Fig. 1A). Clinical diagnosis of $\mathrm{CCH}$ was made and confirmed with FA and OCT (Fig. 1, B through F). On FA, a typical early hyperfluorescence with large vascular spaces and late staining was evidenced (Fig. 1D-E). OCT detailed SRD, revealed a vitreomacular traction (VMT) syndrome (Fig. 1B), and confirmed the anatomy of the dome-shaped tumor on the temporal aspect of the macula (Fig. 1C).

Following informed consent, and after discussing with the patient the current treatment modalities, a session of PDT with verteporfin (Visudyne, Novartis Ophthalmics AG, Basel, Switzerland) at $6 \mathrm{mg} / \mathrm{m}^{2}$ body surface area consisting of three cycles was administered (exposure time of $83 \mathrm{~s}$, laser light of $689 \mathrm{~nm}$ at an intensity of $600 \mathrm{~mW} / \mathrm{cm}^{2}$, and radiant exposure of $50 \mathrm{~J} / \mathrm{cm}^{2}$ ). A spot covering the totality of the tumor area was used. No adverse events such as discomfort, low back pain, chest pain, transient visual loss, catheter-induced complications, or photosensitivity were presented during or immediately after the procedure.

On follow-up, the patient was examined at day 5 after PDT reporting significant visual improvement (hereafter, BCVA refers to the affected eye). His BCVA was of 20/60 and an automated refraction revealed SPH +2.00 and $C Y L-0.75$ OS. Posterior segment fundoscopy revealed an evident reduction of SRD, confirmed by OCT (Fig. 1G-I). On month 2 after PDT, the patient's BCVA remained stable at 20/60. On posterior segment, biomicroscopy atrophic and pigmentary changes were evidenced in the area of the $\mathrm{CCH}$ and macular OCT confirmed a complete retinal reattachment and evidenced VMT syndrome (Fig. 1J-L).

On year 1 of follow-up and after cataract surgery, our patient's BCVA was 20/25 despite VMT syndrome; BCVA remained stable up to year 2 (Fig. 2 A-B). A discussion with detailed explanation of the available surgical procedures was carried out with the patient and the decision to continue his management conservatively was made.

\section{Discussion}

The use of PDT proved to be an excellent monotherapy in our patient with $\mathrm{CCH}$, achieving significant visual and anatomic improvement. Diagnosis of $\mathrm{CCH}$ is made clinically and presents as a solitary roundoval, red-orange, elevated lesion in the parapapillary 

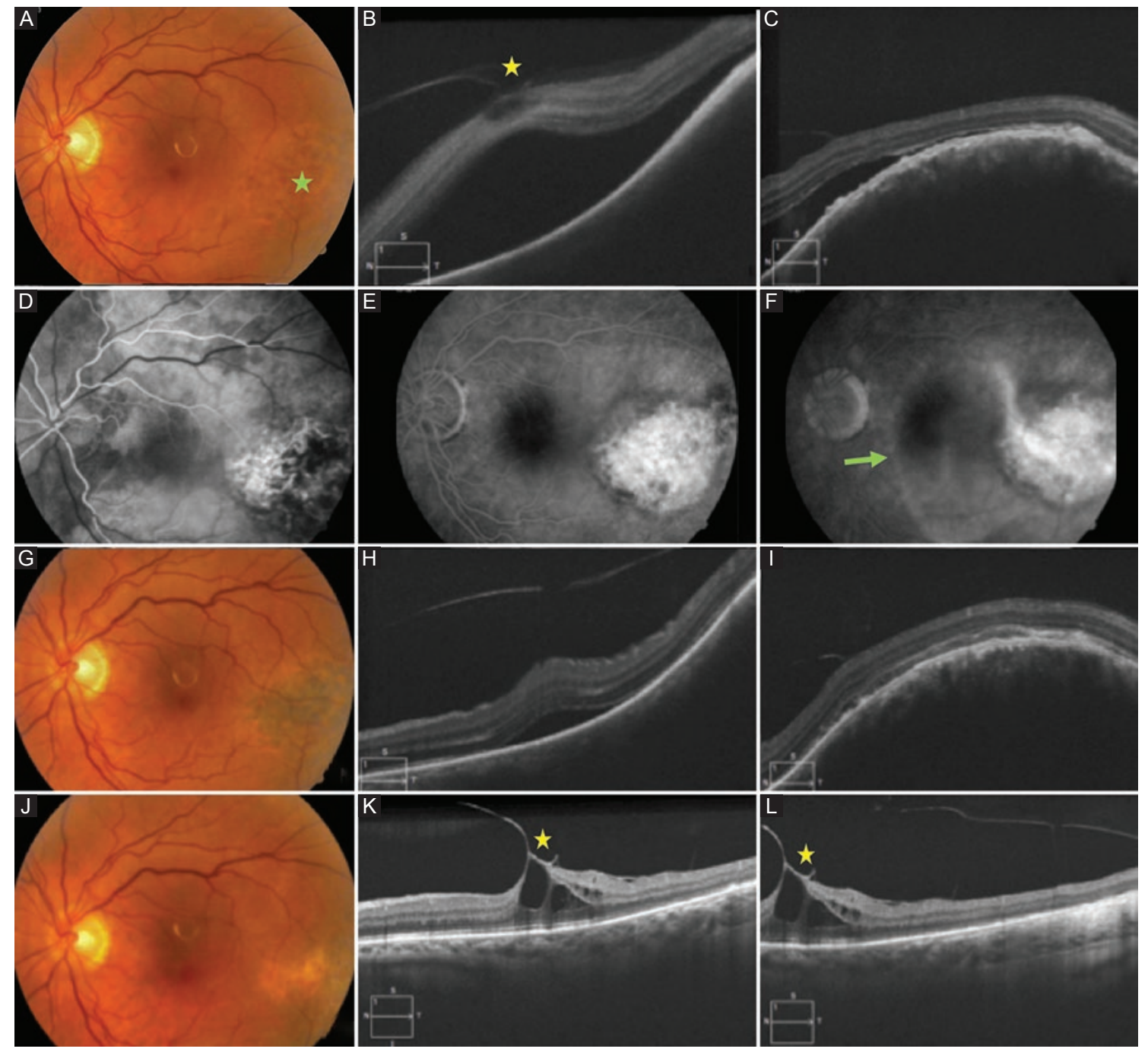

Figure 1. Imaging studies of the left eye of our patient when diagnosed (A-F) and during a 2-month follow-up (G-L) with its corresponding best-corrected visual acuity (BCVA) at the time. (A) color fundus photography of the left eye in which a solitary, circumscribed, round-oval, elevated, mottled, yellow-orange tumor is evidenced in the temporal and inferior macular area (green star), as well as an associated SRD with foveal involvement compatible with a circumscribed choroidal hemangioma; BCVA was of 20/160. (B) high-definition macular OCT revealing VMT syndrome (yellow star) with intraretinal cysts in the fovea, as well as a neurosensory detachment with foveal involvement and a convexity of the retinal pigment epithelium (RPE) temporal to the fovea. (C) high-definition OCT temporal to the fovea in relation with the tumor zone evidencing vitreous schisis, photoreceptor loss, as well as the beginning of the neurosensory detachment near the apex of the tumor together with the convexity of RPE conditioned by the choroidal mass. (D-F) FA, evidencing early hyperfluorescence with large vascular spaces within the tumor in the arterial phase (A), along with late staining on its surface (E, F), SRD is defined on late FA imaging (green arrow). (G-I) color fundus photography 5 days after photodynamic therapy (PDT) evidencing mottled pigmentary changes on the yellow-orange lesion with a significant reduction of SRD (G). Macular OCT confirms the neurosensory reattachment with small remnant of subretinal fluid at the fovea $(\mathrm{H}, \mathrm{I}) ; \mathrm{BCVA}$ of 20/60. (J-L) imaging 2 months after PDT revealing flattening of the tumor, a predominantly yellow coloration of the lesion and full resolution of SRD (J). Macular OCT (K, L) shows VMT syndrome with foveal anatomy disruption and intraretinal cysts (K, L), diagnosed on the initial visit (B). On the temporal aspect of the macula flattening of the tumoral lesion is confirmed and a band of increased reflectivity is appreciated at the choroid in the tumor area (L); BCVA of 20/60.

or macular area ${ }^{9}$. Despite being the $3^{\text {rd }}$ decade of life the most frequent age of diagnosis, our patient was diagnosed in his $8^{\text {th }}$ decade of life. Relevant differential diagnoses are posterior scleritis, central serous chorioretinopathy, wet age-related macular degeneration, retinoblastoma, choroidal metastases, and amelanotic melanoma'.
The treatment of symptomatic $\mathrm{CCH}$ includes techniques such as laser photocoagulation, cryotherapy, brachytherapy, proton beam radiation, and transpupillary thermal therapy ${ }^{1,3,4}$. These modalities of treatment achieve tumor obliteration by producing tissue destruction with chorioretinal scarring/atrophy that results in unfavorable visual 

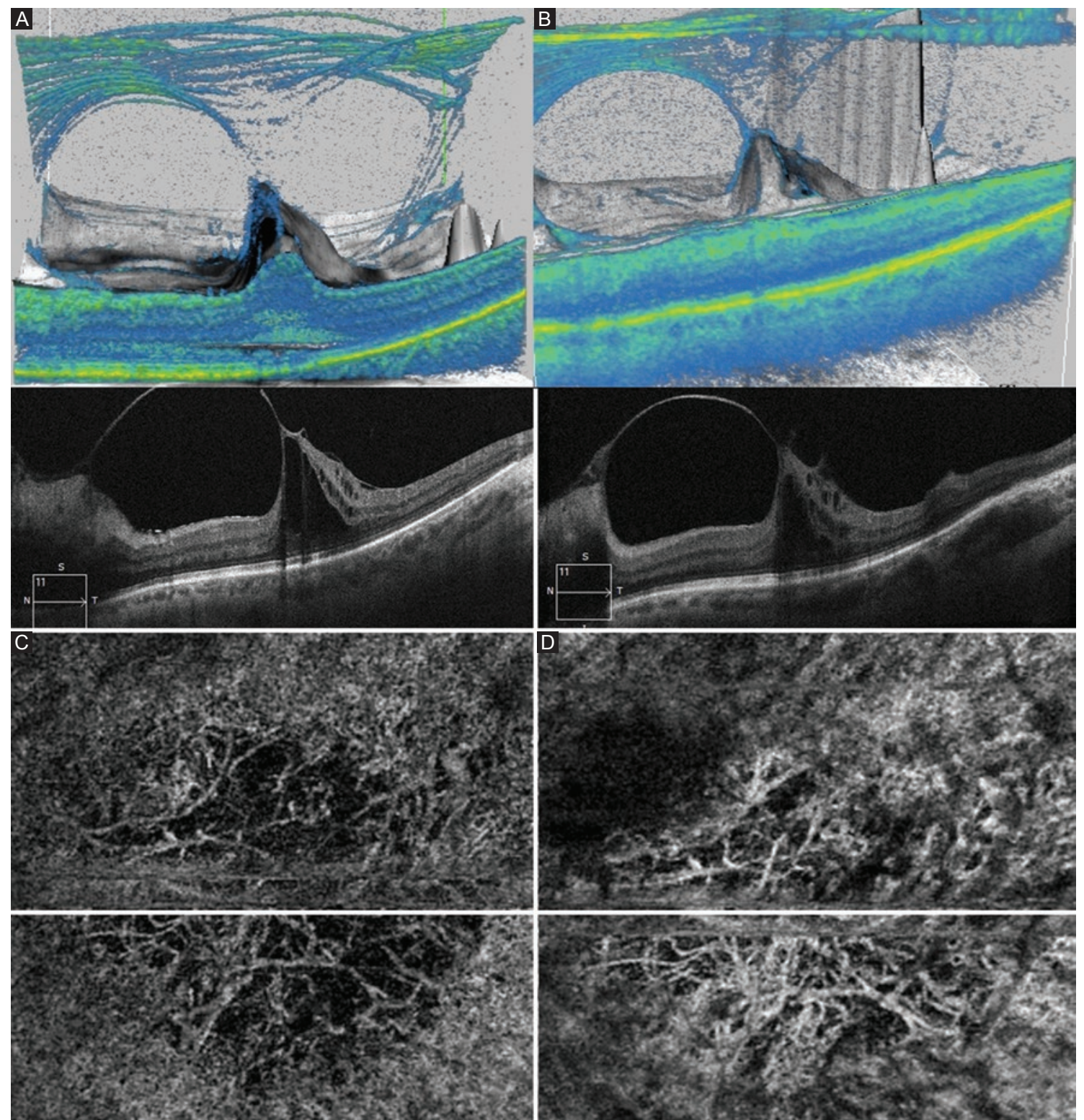

Figure 2. Macular optical coherence tomographic (OCT) imaging (A-B) and OCT-angiography (OCT-A) of the tumor area (C-D). (A) three-dimensional macular OCT cube (top) and high-definition macular OCT (bottom) after 1 year of treatment. VMT syndrome is evidenced, as well as the formation of an epiretinal membrane (ERM) and the presence of vitreopapillary traction. Disruption of the foveal anatomy has increased as well as intraretinal fluid; BCVA of 20/25. (B) same imaging techniques at year 2 after treatment displaying stability of VMT syndrome with a discrete progression of ERM. Foveal anatomy disruption as well as BCVA (20/25) remained stable compared with the year-1 post-treatment. (C) OCT-A of the tumor area at the choriocapillary layer 2 years after treatment evidencing high caliber choroidal vessels surrounded by relatively large avascular areas. (D) choroid layer in OCT-A shows the presence of larger choroidal vessels and smaller avascular areas when compared with the more superficial choriocapillary layer; BCVA of 20/25.

outcomes. Recurrences are common with these procedures $^{3}$. The suitability of these techniques comes to question when the area of treatment involves the macula and/or is located near the fovea $^{1,3,4}$. Theoretically, the use of PDT is the ideal method of treatment due to its selective destruction of endothelial cell membranes of the tumor vascular network and preservation of the overlying retinal cytoarchitecture ${ }^{8}$. A greater volume in the dilated vessels of the hemangioma could play a potentially relevant role increasing the selectivity and effectivity of the treatment ${ }^{5,10}$. As a result, PDT has become the first-line treatment for patients with macular $\mathrm{CCH}^{3,4}$.

PDT with verteporfin is administered at a dose of $6 \mathrm{mg} / \mathrm{m}^{2}$ of body surface area and exposure to a laser 
light dose of 689 or $692 \mathrm{~nm}$ at an intensity of $600 \mathrm{~mW} / \mathrm{cm}^{2}$. The radiant exposure ranges from 50 to $100 \mathrm{~J} / \mathrm{cm}^{2}$. There is no consensus about the treatment parameters. In a study made by Porrini et al. ${ }^{11}$, radiant exposure was titrated according to the height of the lesion. When the measured height was $<2 \mathrm{~mm}$, $75 \mathrm{~J} / \mathrm{cm}^{2}$ with an exposure time of $125 \mathrm{~s}$ was used, and when the height was $>2 \mathrm{~mm}, 100 \mathrm{~J} / \mathrm{cm}^{2}$ with an exposure time of $186 \mathrm{~s}$ was implemented. In addition, some authors apply a single spot covering the entire lesion ${ }^{11,12}$, others use a spot to cover only the most prominent part of the tumor ${ }^{13}$ and others apply 1 or more overlapping spots ${ }^{14}$. The number of sessions ranges from 1 to 5 , at intervals of 6-12 wee$\mathrm{ks}^{1,3,11,13,15,16}$. In all studies, improvement or stabilization of VA, tumor flattening, or regression of macular edema was present as in our case. Our report is of a patient in which a darker iris and more choroidal pigmentation were present. Thus, the reaction to laser treatment is expected to be different than that of reports in different population. In accordance to this matter, parameters were individualized to protect the fovea, as described in the case presentation. Following treatment, anatomical and functional outcomes were positive: BCVA improved on the $1^{\text {st }}$ week after PDT to 20/60, gained four lines of vision after cataract surgery (20/25), and remained stable thereafter despite VMT syndrome.

Cases were $\mathrm{CCH}$ becomes refractory to PDT or where repeated treatments are needed placing the eye at risk for chorioretinal ischemia still remain ${ }^{2}$. Incomplete destruction of the tumor vessels could play a role in this case, and as imaged in our patient, OCT-angiography (Fig. 2 C-D) proves to be a reliable method to assess the vascular cytoarchitecture of $\mathrm{CCH}$. In our current era, where intravitreal antivascular endothelial growth factors (VEGF) have demonstrated to be effective and safe in treating chorioretinal neovascular and exudative conditions, their use as a treatment modality for $\mathrm{CCH}$ comes to mind. Kim et al. ${ }^{2}$ retrospectively evaluated the role of combination therapy of PDT + intravitreal bevacizumab in four eyes of a case series of 11 . In this study, visual improvement was achieved in three of the eyes and one eye achieved visual stabilization. It is argued that anti-VEGF agents pose a synergistic effect with PDT, and that their use can be useful as adjuvant therapy to avoid the described decline in VA following PDT due to the rise in VEGF ${ }^{17}$, in parapapillary lesions that about the optic nerve ${ }^{3}$, and in patients with media opacities, overlying hemorrhage or cases with active exudation?2.

\section{Conclusion}

Our report supports the safety and effectiveness of PDT as monotherapy in cases of $\mathrm{CCH}$ with macular involvement and SRD. It additionally provides evidence of possible safe parameters of PDT with verteporfin for eyes with darker irides and increased choroidal pigment content and documents OCT anatomical changes during time. We recommend the use of PDT with verteporfin as the first-line therapy and reserve the use of anti-VEGF for select cases in which PDT has proven insufficient or cases in which media opacities impede the correct application of the laser. Clinical trials in our population are needed to precisely characterize the effect of PDT and define the best treatment technique for each case.

\section{Conflicts of interest}

The authors declare no financial or commercial conflicts of interest.

\section{Ethical Disclosures}

Protection of human and animal subjects. The authors declare that no experiments were performed on humans or animals for this study.

Confidentiality of data. The authors declare that no patient data appear in this article.

Right to privacy and informed consent. The authors declare that no patient data appear in this article.

\section{References}

1. Shields CL, Honavar SG, Shields JA, Cater J, Demirci H. Circumscribed choroidal hemangioma: clinical manifestations and factors predictive of visual outcome in 200 consecutive cases. Ophthalmology. 2001; 108:2237-48.

2. Kim H, Wang A, Mititelu M. Case series of anti-vascular endothelial growth factor and photodynamic therapy in the treatment of circumscribed choroidal hemangiomas. J Vitro Retin Dis. 2017;1:133-7.

3. Boixadera A, García-Arumí J, Martínez-Castillo V, et al. Prospective clinical trial evaluating the efficacy of photodynamic therapy for symptomatic circumscribed choroidal hemangioma. Ophthalmology. 2009;116:100-50.

4. Zhang Y, Liu W, Fang Y, et al. Photodynamic therapy for symptomatic circumscribed macular choroidal hemangioma in Chinese patients. Am J Ophthalmol. 2010;150:710-50.

5. Shields JA, Shields CL, Materin MA, et al. Changing concepts in management of circumscribed choroidal hemangioma: the $2003 \mathrm{~J}$. Howard stokes lecture, part 1. Ophthalmic Surg Lasers Imaging. 2004;35: 383-94.

6. Blasi MA, Tiberti AC, Scupola A, et al. Photodynamic therapy with verteporfin for symptomatic circumscribed choroidal hemangioma: five-year outcomes. Ophthalmology. 2010;117:1630-7.

7. Elizalde J, Vasquez L, lyo F, Abengoechea S. Photodynamic therapy in the management of circumscribed choroidal hemangioma. Can J Ophthalmol. 2012;47(1):16-20.

8. Cerman E., Çekiç O. Clinical use of photodynamic therapy in ocular tumors. Surv Ophthalmol. 2015;60:557-74. 
9. Agarwal A, Gass JD. Gass' Atlas of Macular Diseases. $5^{\text {th }}$ ed. Edinburgh: Elsevier Saunders; 2012.

10. Mashayekhi A, Shields CL. Circumscribed choroidal hemangioma. Curr Opin Ophthalmol. 2003;14:142-9.

11. Porrini G, Giovannini A, Amato G, Ioni A, Pantanetti M. Photodynamic therapy of circumscribed choroidal hemangioma. Ophthalmology. 2003;110:674-80.

12. Schmidt-Erfurth UM, Michels S, Kusserow C, Jurklies B, Augustin AJ Photodynamic therapy for symptomatic choroidal hemangioma: visual and anatomic results. Ophthalmology. 2002;109:2284-94.

13. Verbraak FD, Schlingemann RO, Keunen JE, de Smet MD. Longstanding symptomatic choroidal hemangioma managed with limited PDT as initial or salvage therapy. Graefes Arch Clin Exp Ophthalmol. 2003;241:891-8.
14. Singh AD, Kaiser PK, Sears JE, et al. Photodynamic therapy of circumscribed choroidal haemangioma. Br J Ophthalmol. 2004;88:1414-8.

15. Michels S, Michels R, Beckendorf A, Schmidt-Erfurth U. Photodynamic therapy for choroidal hemangioma. Long-term results. Ophthalmologe. 2004:101:569-75.

16. Jurklies B, Anastassiou G, Ortmans S, et al. Photodynamic therapy using verteporfin in circumscribed choroidal haemangioma. $\mathrm{Br} \mathrm{J}$ Ophthalmol. 2003:87:84-9.

17. Schmidt-Erfurth U, Schlötzer-Schrehard U, Cursiefen C, et al. Influence of photodynamic therapy on expression of vascular endothelial growth factor (VEGF), VEGF receptor 3, and pigment epithelium-derived factor. Invest Ophthalmol Vis Sci. 2003;44:4473-80. 